\title{
A Two-Stage Stochastic Optimization for Robust Operation of Multipurpose Reservoirs
}

\section{J. Pablo Ortiz-Partida ${ }^{1,2}$ (D) Taher Kahil $^{1} \cdot$ Tatiana Ermolieva $^{1} \cdot$ Yuri Ermoliev $^{1}$. Belize Lane $^{3}$ - Samuel Sandoval-Solis ${ }^{2}$ - Yoshihide Wada ${ }^{1}$}

Received: 8 December 2018 / Accepted: 5 August 2019 /

Published online: 19 August 2019

(C) The Author(s) 2019

\begin{abstract}
Robust reservoir operation has long been considered a promising solution for addressing water allocation problems in the absence of reliable hydroclimatic forecasts. This study aims to evaluate the performance of this solution using a novel two-stage stochastic optimization model. The model maximizes economic benefits from reservoir deliveries while integrating stochastic inflows into a water allocation system with multiple demands and various constraints. The outcome of the model is a robust set of monthly reservoir releases that perform well under a wide range of hydroclimatic conditions. The model has been applied to the case of the Big Bend Reach of the Rio Grande/Bravo, a transboundary river basin of high importance for Mexico and the United States. The performance of the robust operation policy was assessed by comparing its outcome to those obtained under observed historical operations and an operation policy derived from a deterministic version of the optimization model that assumes perfect hydroclimatic knowledge. The results of this study indicate that the set of robust releases developed here outperforms historical reservoir operations and performs similarly to operations under perfect knowledge. These results show the effectiveness of robust reservoir operation and the usefulness of the proposed optimization model for decision-making under increasing hydroclimatic uncertainty.
\end{abstract}

Keywords Multipurpose reservoir · Uncertainty · Stochastic optimization · Rio Grande/Bravo

\footnotetext{
Highlights

- This study develops a novel two-stage linear stochastic optimization model that includes various water supply objectives with predefined safety levels.

- The stochastic model could be particularly useful for improving reservoir operations under the increasing hydroclimatic uncertainty.

- The stochastic model outcomes outperform those obtained under observed historical operations and performs almost similarly to the outcomes of a deterministic model with perfect hydroclimatic knowledge.
}

Electronic supplementary material The online version of this article (https://doi.org/10.1007/s11269-01902337-1) contains supplementary material, which is available to authorized users.

J. Pablo Ortiz-Partida joportiz@ucdavis.edu

Extended author information available on the last page of the article 


\section{Introduction}

Thousands of reservoirs around the world contribute to human development by providing a more reliable water supply, flood control, hydropower generation, and other benefits. However, the social and environmental costs associated with the development of reservoirs and their operations have remained unacceptably large in several major river basins (WCD 2000), including the Colorado, Yangtze, and Mekong (Thompson 2008). One important challenge in the coming decades is to identify ways of improving the operation of multipurpose reservoirs (Mateus and Tullos 2017), especially under increasing hydroclimatic uncertainty driven by climate change (Seneviratne et al. 2012). For instance, flood occurrences have increased by $26 \%$ globally and $20 \%$ in the United States in the last decades (Berghuijs et al. 2017). Moreover, the annual average costs associated with floods and droughts in the United States amount to 3 and 6 billion USD, respectively (Smith 2018). Considering that a major part of irrigated agriculture is supported by reservoirs and that millions of people depend on dams for flood protection, such costs could be considerably reduced by improved reservoir operations.

Developing efficient operation policies for multipurpose reservoirs is, however, a challenging task. In spite of having complementary objectives, different water use sectors often place conflicting water management goals on such reservoirs (Labadie 2004). For instance, a water supply objective might require water elevation to be maintained near maximum storage to increase water supply reliability, while flood management would advocate for a much lower water elevation with the capacity to manage high, possibly catastrophic, inflows to reduce the risk of overtopping. Integrating environmental flow requirements as another objective could introduce further competition. These water use trade-offs are traditionally managed by reservoir operation policies that dictate the range of storage and water elevation at the surface of the reservoir at the end of each month. Operation policies divide the reservoir into different storage zones that are used for water supply, recreation, hydropower, or flood management (Labadie 2004). Given the considerable uncertainty associated with water inflows, however, the effectiveness of this traditional end-of-month storage operation of multipurpose reservoirs is becoming questionable.

The objective of this study is to identify a robust reservoir operation policy that encompasses hydroclimatic uncertainty and improves water management by increasing regional economic benefits and reducing environmental impacts. To meet this objective, we develop and apply a novel two-stage stochastic optimization model that integrates multiple water management objectives under uncertain hydroclimatic conditions. The performance of the robust operation policy is assessed by comparing its outcome to: (1) outcomes obtained under observed historical operations, and (2) an operation policy derived from a deterministic version of the optimization model that assumes perfect hydroclimatic knowledge.

This paper is organized as follows. First, a review of optimization techniques to develop reservoir operation policies with a special focus on the area of stochastic optimization of water resources is provided in Section 2. Section 3 describes the proposed optimization model. Section 4 describes the study area, and Section 5 presents the results of applying the model and discusses the value of developing robust reservoir operations. Section 6 summarizes the main conclusions. 


\section{Background}

\subsection{Optimizing Reservoir Operation}

Since the 1960s, the optimization of reservoir operation has gained importance as one of the main research areas in water resources management (Yeh 1985). Different reservoir optimization methods have been used, including linear, non-linear, and dynamic programming with different limitations, such as, respectively, linearizing non-linear variables, finding non-global optima, and a heavy computational burden (Yeh 1985; Husain 2012).

Traditional deterministic optimization models are scenario-dependent, meaning that certain variables such as reservoir inflows, water demands, or system losses are parameters in the models. This is because only statistical descriptions of hydrologic variables or unreliable forecasts of long-term average conditions usually exist. Consequently, deterministic optimization models may fail to include the impacts of low probability but costly events such as floods or droughts (Farmer and Vogel 2016).

Another approach to incorporating variability into the optimization model is to include stochasticity in model inputs. However, reservoir operators are often skeptical of using optimization models with such complexity (Celeste and Billib 2009; Motta de Santana Moreira and Celeste 2017). In recent years, with the improvements in simulation models and computational power, intelligent computational programming has been developed. A prevalent example is Evolutionary Computation, a programming technique with different optimization algorithms such as Genetic Algorithms, Particle Swarm Optimization, Simulated Annealing, Honey Bees Mating, and Artificial Neural Networks. Choong and El-Shafie (2015) provide a comprehensive review of the use and application of these techniques for reservoir management.

\subsection{Stochasticity in Reservoir Operation}

The uncertainty underlying several hydrologic processes has led to the development of stochastic optimization techniques in water resources that integrate random or unknown variables such as precipitation, streamflow, or water demands. These techniques have been applied to derive operation rules for single reservoir (Butcher 1971; Saadat and Asghari 2019) and multi-reservoir systems (Stedinger et al. 2013; Macian-Sorribes et al. 2017; Zatarain Salazar et al. 2017) under uncertain hydroclimatic conditions. An example is the Linear Decision Rule (LDR) introduced by Revelle et al. (1969), which specified reservoir releases based on the difference in the initial storage and a decision parameter for a particular period. Such parameters include hydropower generation targets, water allocation rights, and minimum navigation flow requirements. Linear problems, however, tend to have explicit single objectives and consider environmental water demands as constraints within the model.

Stochastic non-linear problems have also been developed in the literature. The Stochastic Dual Dynamic Programming (SDDP) approach was successfully applied to develop reservoir operation policies for multi-reservoir systems (Pereira and Pinto 1991; Tilmant and Kelman 2007) and later extended and applied to the Jucar basin in Spain to explicitly include streamaquifer interactions (Macian-Sorribes et al. 2017). Another approach is Sampling Stochastic Dynamic Programming (SSDP) developed to investigate methods of increasing the water allocation efficiency of multi-reservoir operations in the Geum River basin of Korea (Kim et al. 2007; Eum et al. 2010). SSDP incorporates the annual correlation of streamflow from 
historical or synthetic data by combining different streamflow scenarios within the optimization model. Compared with a deterministic approach using average streamflow, the results show improved performance if inflow uncertainty is explicitly included into the modeling process (Kim et al. 2007). Gaivoronski et al. (2012) developed a scenario-based stochastic optimization method of a water resources system to obtain robust policies that minimize the risk of wrong decisions and allow the user to implement an emergency policy under a reoptimization phase. These non-linear problems tend to become computationally intensive and do not guarantee global optimal solutions.

Pan et al. (2015) developed an Iterative Linear Decision Rule (ILDR) to provide a tractable approximation for a multi-period hydropower generation problem. This modification of the LDR, which enables the integration of non-linear objective functions using piece-wise linearization, is considered a robust optimization approach. The researchers applied ILDR to the single reservoir system of the Three Gorges Dam in China and to the Shasta-Trinity multi-reservoir system in California. The results of this application show that ILDR performance is similar to SSDP when implemented on the original historical inflows and that it improves performance when tested on generated inflows.

Stochastic optimization has been proven to reduce the potential risk of erroneous decisions when compared with deterministic approaches. Celeste and Billib (2009) assessed the performance of different stochastic methodologies to define optimal reservoir operations by comparing them with the solution of a deterministic model that assumed perfect knowledge of all future monthly inflows. This allowed them to measure the performance of the stochastic models relative to first-best operations.

Similar to the models previously developed by Kim et al. (2007), Eum et al. (2010) and Macian-Sorribes et al. (2017), our study presents an optimization model that explicitly includes the uncertainty related to water inflows into reservoirs. However, our model addresses the highly nonlinear, nonconvex, and non-smooth constraints typically included in stochastic optimization using two-stage linear programming. These features make our model capable of including a variety of water supply objectives with predefined safety levels, allowing a robust policy to be derived that, in the long term, would be suitable regardless of the inflow scenario (Ermoliev et al. 2019). The contributions of this study to the literature are as follows: (1) it includes the development of a novel two-stage linear stochastic optimization model that incorporates performance indicators for multiple water management objectives such as water supply, flood risk reduction, and environmental flow requirements; (2) it strengthens the importance of considering stochastic inflows in the modeling of reservoir operations; and (3) it derives a robust set of adaptable reservoir releases instead of the traditional end-of-month reservoir storage operation.

\section{Modeling Framework}

\subsection{Problem Formulation}

This paper develops a stochastic optimization model to obtain a set of robust monthly reservoir releases that maximize the economic benefits of water use. We begin by briefly describing a traditional deterministic optimization formulation of reservoir management and then describe the proposed stochastic formulation. 
A traditional deterministic approach considers a planning horizon of $T$ periods divided into smaller time steps $t$. Typical variables for deterministic reservoir operations are those in the mass balance equation (Eq. 1), which states that the storage at a given time $S_{t}$ is equal to the storage in the previous time step $S_{t-1}$ plus the inflows $I_{t}$ minus the releases $R_{t}$ and evaporation losses $E_{t}$, as follows:

$$
S_{t}=S_{t-1}+I_{t}-R_{t}-E_{t}
$$

The objective function (Eq. 2) of this model maximizes the total benefits from water use $F(R)$, which are equal to the sum of the benefits of individual water users $i, b_{i}$, as a function of reservoir releases $R_{i t}$ in each time step $t$, subject to the water balance equation and other physical reservoir constraints, as follows:

$$
\operatorname{Max} F(R)=\sum_{i} \sum_{t=1}^{T} b_{i t}\left(R_{i t}\right)
$$

This problem of reservoir management can be reformulated as a two-stage stochastic optimization model in which benefits, costs, and water demands are treated as parameters and inflows are unknown and variable. The first stage decisions involve water releases from the reservoir based on a whole-system expected deficit. In the second stage, once the deficit is known, it is allocated among users (Fig. 1).

To allow the flow of excess water, a surplus variable is also integrated within the second stage. The advantage of using this two-stage stochastic formulation is the ability to address problems of input data uncertainty (Huang et al. 2012). Under the first stage, the model decides without knowing exact information about the inflows and expected deficits or surpluses, whereas in the second stage, the model hedges the deficit for optimal water supplies to the

\section{Inputs/parameters}

- Monthly water demands by user

- Benefits per unit of water supplied

- Physical reservoir characteristics

- Cost per unit of water deficit

- Other cost per unit above certain threshold (e.g., floods)
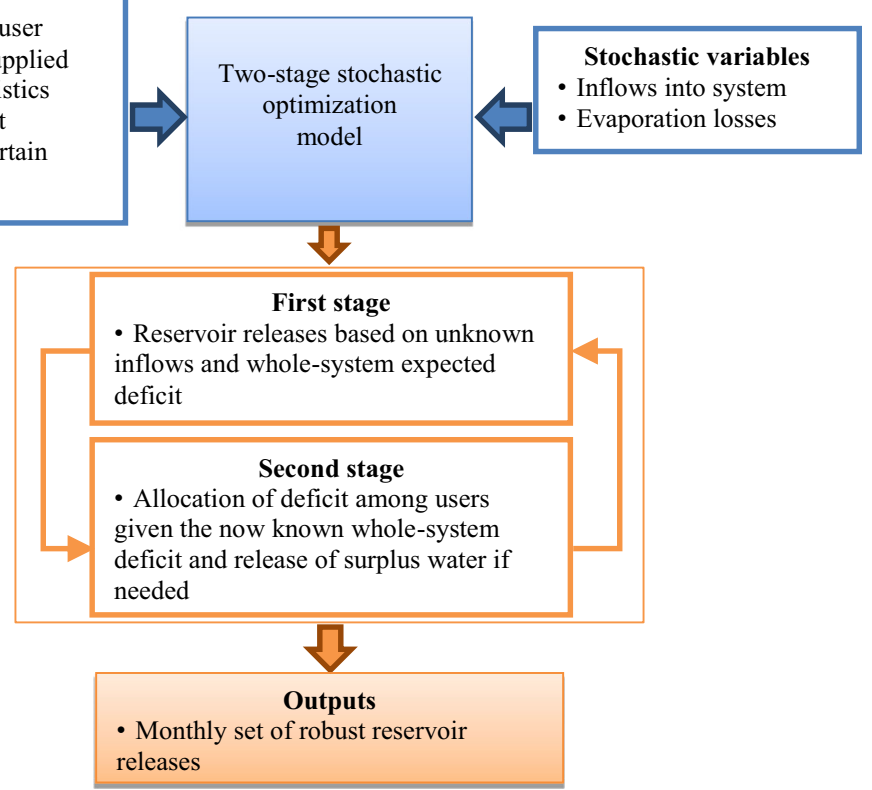

Fig. 1 Stochastic optimization model workflow 
system considering the now disclosed variables. Ermolieva et al. (2016) implemented a similar approach for flood mitigation and land use management. The objective function of the proposed two-stage stochastic optimization model is depicted in Eq. 3, and its linearized form is shown in Eqs. 4 to 9, as follows:

$$
\begin{aligned}
\operatorname{Max} F\left(R_{m}\right) & =\sum_{m} \sum_{i} b_{i m} \cdot R R_{i m} \\
& -\sum_{s=1}^{S} \sum_{m} \sum_{i} d_{i} i C_{i m} \cdot p_{m}^{s} \cdot \max \left\{0, d_{i m}-R R_{i m}\right\} \\
& -\sum_{s=1}^{S} \sum_{m} \sum_{i} s u i C_{i m} \cdot p_{m}^{s} \cdot \max \left\{0, R R_{i m}-d_{i m}\right\}
\end{aligned}
$$

The objective function of the model (Eq. 3) is to maximize net benefits from fulfilling water demands and to minimize occurrences of scenario-specific water deficits $\max \left\{0, d_{i m}-R R_{i m}\right\}$ and surpluses $\max \left\{0, R R_{i m}-d_{i m}\right\}$ to user $i$ where $d_{i m}$ defines water demand by user $i$ in month $m, R R_{m i}$ is water supplied to users $i$ in month $m, s$ denotes a water inflow scenario and $S$ is the number of scenarios (years with inflow records). $b_{i m}$ denotes net benefits per unit of water supplied to each user $i$ (e.g., irrigated agriculture, urban water supply, environmental flows) in different months $m=1, \ldots, 12$; dei $C_{i m}$ and $s u i C_{i m}$ are the cost associated with expected deficits $\sum_{s=1}^{S} p_{m}^{s} \max \left\{0, d_{i m}-R R_{i m}\right\}$ and surpluses $\sum_{s=1}^{S} p_{m}^{S} \max \left\{0, R R_{i m}-d_{i m}\right\}$ for each user $i$, respectively. $\mathrm{dei}_{i m}$ characterizes, in a sense, the price of water (or losses associated with deficits) for water user $i$ in month $m$, and sui $C_{i m}$ identify losses associated with water oversupply such as flooding or excess water to agriculture. $p_{m}^{s}$ is the probability of occurrence of inflow scenario $s$, which is assumed to be equal to $1 / S$. A random scenario generator can be incorporated into the optimization when a limited number of records are available or to include a broader range of scenarios (Ermoliev and Wets 1988). In this proposed model, reservoir releases $R_{m}$ and water supplied to users $R R_{m i}$ are strategic first-stage decisions, which do not depend on a specific inflow scenario. Scenario-specific water deficits and surpluses correspond to secondstage decisions. Benefits from water supply are maximized, and costs/losses due to possible deficits and surpluses are minimized. The optimal combination of the first- and the secondstage decisions brings robustness into the resultant set of monthly reservoir releases.

The surplus $\max \left\{0, d_{i m}-R R_{i m}\right\}$ and deficit $\max \left\{0, R R_{i m}-d_{i m}\right\}$ variables are non-smooth (due to max operations), and their use in the objective function would lead to a non-smooth stochastic optimization problem (Ermoliev and Wets 1988). To linearize the objective function (3), we introduce the terms deficits $D e_{m i}^{s}=\max \left\{0, R R_{i m}-d_{i m}\right\}$ and surpluses $S u_{m i}^{s}=\max \left\{0, d_{i m}-R R_{i m}\right\}$, and add constraints (8) and (9), making $D e_{m i}^{s}$ and $S u_{m i}^{s}$ stochastic positive variables implicitly dependent on inflows $\left(I_{m}^{s}\right)$ and giving the following linear formulation:

$$
\begin{array}{r}
\operatorname{Max} F\left(R_{m}\right)=\sum_{m} \sum_{i} b_{i m} \cdot R R_{i m}-\sum_{s=1}^{S} \sum_{m} \sum_{i} \operatorname{dei} C_{i m} \cdot p_{m}^{s} \cdot D e_{m i}^{s} \\
-\sum_{s=1}^{S} \sum_{m} \sum_{i} s u i C_{i m} \cdot p_{m}^{s} \cdot S u_{m i}^{s}
\end{array}
$$

subject to:

$$
R_{m}=\sum_{i}^{I} R R_{i m}
$$




$$
\begin{gathered}
\underline{s}_{m}^{s} \leq S_{m}^{s} \leq \bar{s}_{m}^{s} \\
S_{m+1}^{s}=S_{m}^{s}+I_{m}^{s}-R_{m}-E_{m}^{s}-\sum_{i} S u_{m i}^{s}+\sum_{i} S e_{m i}^{s} \\
D e_{m i}^{s} \geq d_{i m}-R R_{i m} \\
S u_{m i}^{s} \geq R R_{i m}-d_{i m}
\end{gathered}
$$

The objective function (Eq. 4) is maximized subject to several constraints (Eqs. 5 to 9). Equation 5 states that the sum of reservoir releases for each user must be equal to the total release from the reservoir. Equation 6 defines the minimum and maximum reservoir storage allowed in each month and year (i.e., scenario). Equation 7 includes the reservoir water balance for the storage $S$ in each time-step including $S u_{m i}^{s}$ and $D e_{m i}^{s}$ variables. The purpose of the $S u_{m i}^{s}$ variable is to reduce the storage before months in which high flows are more probable, and the purpose of the $D e_{m i}^{s}$ variable is to hold water before months that are prone to deficits. By regulating the costs of surplus $s u i C_{i m}$ and deficit $d e i C_{i m}$, which can also be interpreted as risk weights, in the maximization of the objective function (4) under constraints (5) to (9), it is possible to avoid surpluses and deficits with predefined probabilities. Equation 8 limits the deficits to the amount of maximum allocation for each user. Equation 9 quantifies the surplus and allows high inflows to be released to avoid or reduce overtopping.

The two-stage formulation, as noted in the last two terms of the objective function (Eq. 4), induces safety constraints on the water supply based on the probability of deficits and surpluses. Such constraints are known as probability or chance constraints in stochastic optimization, stability constraints in the insurance business, and constraints on the Value-atRisk (VaR) in financial applications (Ermoliev and Wets 1988). These constraints represent the worst-case loss associated with a probability in set time period. In dealing with these highly nonlinear, nonconvex, and often discontinuous safety constraints, we use connections with minimization of so-called Conditional Value-at-Risk (CVaR) functions. CVaR represents the expected losses if the worst-case threshold of loss is ever crossed and it is considered a more consistent measure of risk than VaR. In our problem, where uncertainty originates from a finite number of scenarios, the problem can be efficiently solved using linear programming (Rockafellar and Uryasev 2000).

\subsection{Performance Criteria}

Four criteria were used to evaluate the performance of observed data and simulations under the different model formulations: time-based reliability $\left(\operatorname{Rel}_{\mathrm{t}}\right)$, volumetric reliability $\left(\operatorname{Rel}_{\mathrm{v}}\right)$, resilience (Res), and vulnerability (Vul) (Hashimoto et al. 1982). Time-based reliability is the probability of fulfilling water demands over the period of simulation; volumetric reliability quantifies the total volume of water supplied divided by the total water demand for each user on each time step; resilience is a measure of the ability of the system to recover after a failure; and vulnerability is a measure of the severity of a deficit. Moreover, we used the sustainability index, referring to the geometric average of the four criteria for each water user, as an 
integrated measure of performance (Sandoval-Solis et al. 2011). A more detailed description of the performance criteria is provided in the Online Supplementary Material.

\section{Model Application to a Single Reservoir System}

\subsection{Description of the Study Area}

We applied the proposed optimization model to a single reservoir system in the lower Rio Conchos, the main tributary of the transboundary Rio Grande/Bravo (RGB). The Rio Conchos is the main water source of the Big Bend Reach (BBR) of the RGB. The BBR is a region of recognized binational importance, where water availability, water quality, flood risk, and the preservation of recreational activities and of the aquatic and riparian ecosystems of the Chihuahuan Desert are fundamentally important to the region's welfare (Obama and Calderón-Hinojosa 2010). This study extends over the Rio Conchos river channel from the Luis L. León Reservoir (LLL) in Mexico to the confluence with the RGB mainstream in the Presidio and Ojinaga (P-O) Valley (Figure SM1 in Online Supplementary Material). LLL has three storage zones: inactive, conservation, and flood control. The inactive storage is $50 \mathrm{Mm}^{3}$, the top of conservation is $292.46 \mathrm{Mm}^{3}$ (as it was originally designed for flood control), and the total storage of the reservoir is $832 \mathrm{Mm}^{3}$ (CONAGUA 2011). However, the historical operation of LLL does not follow the nominal top of conservation, and the average historical operation storage is between $580 \mathrm{Mm}^{3}$ in the wet season and $700 \mathrm{Mm}^{3}$ in the dry season (Lane et al. 2015). LLL reservoir operations are based on the conflicting objectives of maximizing the amount of available water in storage for supply purposes (e.g., irrigation, municipal) and maximizing the floodwater storage capacity to reduce downstream flood damage, all while meeting international delivery commitment under the 1944 treaty (IBWC 1944).

Several optimization models have been previously developed for this study area. Cañón et al. (2009) created a two-stage non-linear optimization model to minimize water deficits to users and maximize irrigated crop production. Their study considered a Drought Frequency Index, which is a stochastic index that offers a mean return period of an integrated measure of a drought severity and duration. Porse et al. (2015) developed a linear optimization model that minimizes water deficit for different users. However, these two optimization models are not stochastic, and their underlying objective functions are different from those considered here.

\subsection{Model Input Data and Variables}

The stochastic formulation presented in section 3 has been applied to the study area. GAMS software was used for model development and scenario simulation (Brooke et al. 1988). A detailed description of the empirical model equations and data specific to the study area can be found in the Online Supplementary Material. Data include urban and agricultural water demands below LLL in the Rio Conchos and downstream of P-O valley as well as the economic benefits of water supplies and the cost of deficits to each user. Additional inputs include monthly reservoir inflows from the Rio Conchos-Las Burras streamflow gauge from 1969 to 2010 and the estimated monthly evaporation.

The environmental flow (EF) requirements developed by the Rio Grande Expert Science Team (2012) have here been adopted as another water demand in the system. These EF requirements have been used in previous studies (Porse et al. 2015; Lane et al. 2015). We have 
also incorporated costs related to flood damage caused by monsoons coming from the Gulf of Mexico and the Pacific (IBWC 1971; Sayto-Corona et al. 2017). Other input data are reservoirs and flood infrastructure features, and international delivery commitment from Mexico to the United States.

As the monthly time step of this model cannot adequately capture the performance of operation policies with respect to flood events, a proxy of flood probability was considered. A probability analysis was conducted to identify the historic monthly flow volume $\left(550 \mathrm{Mm}^{3}\right.$ at the Presidio gauge station) corresponding to daily flow values exceeding the design capacity of the levee $\left(1190 \mathrm{~m}^{3} / \mathrm{s}\right)$ (Lane et al. 2015). We used this value to identify the number of months which are prone to flood events. During the 42-year period of historical records, there were 4 flood events representing a $10.5 \%$ flood probability. Flood probability in this study is defined as the number of years when monthly flow volumes at Presidio are higher than $550 \mathrm{Mm}^{3}$, divided by the period of records.

The monthly economic value per unit of water delivered was estimated taking into account agricultural revenue and water applied to agriculture from 1997 to 2013 according to irrigation district statistics from Mexico (CONAGUA 1997-2013). When users do not receive promised water, they have to either obtain it via more expensive alternatives (e.g., groundwater, treated wastewater, or water transfer) or to modify their development plans (e.g., changing crop patterns or reducing irrigated area). Associated penalties include the costs of water acquisition from alternative sources and the cost of changing development plans. To quantify economic benefits for agriculture, we used the economic values derived by Ortiz-Partida et al. (2016).

\section{Results and Discussion}

\subsection{Reservoir Operation Under Alternative Model Formulations}

Based on comparisons between observed and simulated reservoir storage and flow at Presidio gauge, the deterministic model (with perfect knowledge of future inflows) was able to avoid some of the floods (Fig. 2b) compared to historical observations (Fig. 2a). However, given the limited storage capacity and the periodic intensity of reservoir inflows, some flood events were unavoidable. Under the stochastic model, storage was characterized by releases that decreased water levels every summer during the monsoon season (August and September) to reduce costly future flood events in spite of long-term deficits (Fig. 2c). This model resulted in highly variable storage from year to year because it calculated storage in each year independently instead of carrying over the storage from the previous year as in the deterministic model.

The stochastic model was capable of reducing the intensity and frequency of flood events compared to historical observations. Historically, there were four flood events in P-O valley in the years 1978, 1990, 1991, and 2008 (Fig. 2d). Two of these flood events were avoided under both the deterministic and stochastic models and, when floods were unavoidable, the magnitude of the events was reduced (Fig. 2e, f). Consequently, the deterministic and stochastic models could, respectively, reduce the historical economic damage caused by flood events ( 1.17 million USD/year) by 0.5 and 0.4 million USD per year.

Figure 3 depicts observed and simulated reservoir releases and system deficits. Historical water deliveries from LLL were for the most part inefficient because water was released at times when it was not needed, probably due to a conservative flood management operation. Therefore, releases were larger under the historical observation, with larger deficits occurring 

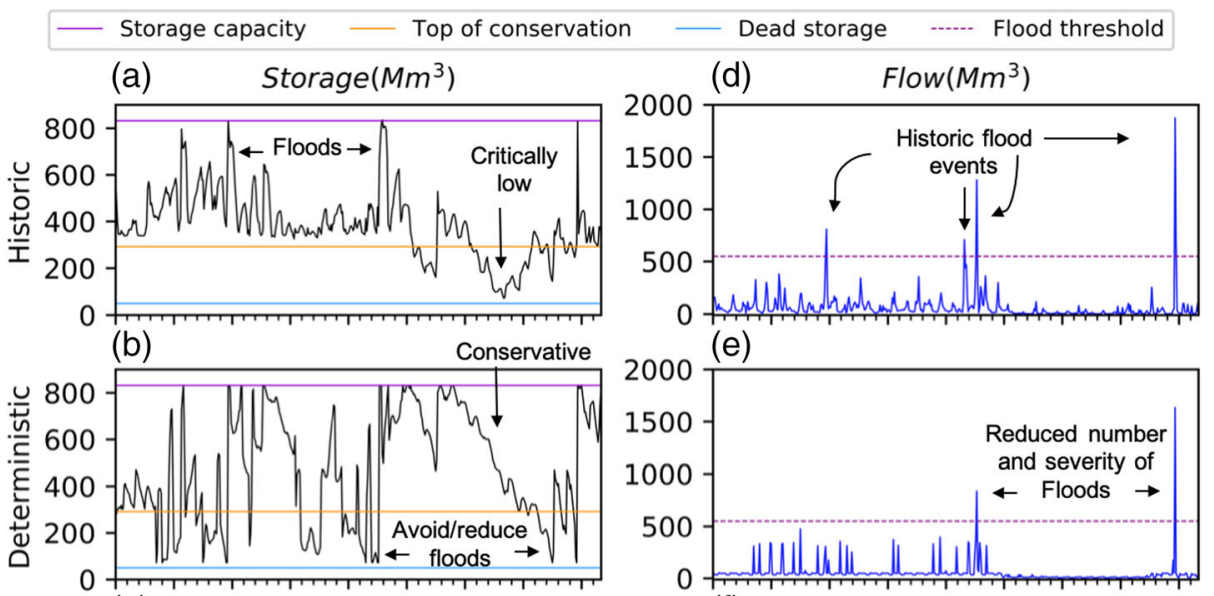

(c)
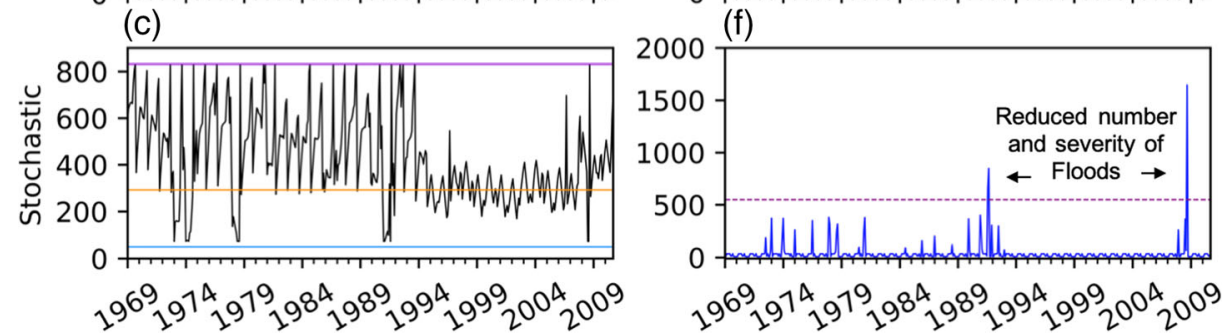

Fig. 2 Historical observation, deterministic, and stochastic reservoir storage and flow at Presidio

due to frequent smaller releases. For example, over the period from 1979 to 1987 (Fig. 3ainset), a considerable number of releases were above the water demand. Under the stochastic model, expected deficits were often overcome when water was released to avoid overtopping. Such releases were robust because they minimized losses from deficits and surpluses within the system. An example is the drought period from 1993 to 2006 when deficits were even higher under the deterministic model (Fig. 3e, f). This is possible because the deterministic model considers only perfect knowledge of inflow conditions for 1 month in advance, while the stochastic model considers a wide range of possible hydroclimatic events.

Results from Fig. 3 show that for the deterministic and stochastic models, all the deficits are allocated to the environment because environmental flows have lower priority. To reduce water deficits for the environment, the deficit could be shared across users. Previous research shows that economic benefits from improved environmental outcomes such as reduced spending on the reintroduction of silvery minnow, an endangered regional fish species, may outweigh the costs of increased deficits to other users (Ortiz-Partida et al. 2016).

Figure 4 presents the economic outcomes for the different uses under the historical observation and the stochastic and deterministic models. Total net benefits from water use in the study area, including agricultural and environmental benefits and flood costs, amount to 5.5 million USD/year. These benefits could increase substantially under both the deterministic (22.9 million USD/year) and stochastic (19.2 million USD/year) models. Most of these increases in the two models originate from the avoided deficits in irrigated agriculture. Given that the three models consider the same water availability (same reservoir inflows), the deterministic and stochastic models show that timing of reservoir releases is of great importance to reduce deficits. Irrigated agriculture could achieve higher benefits in the deterministic 


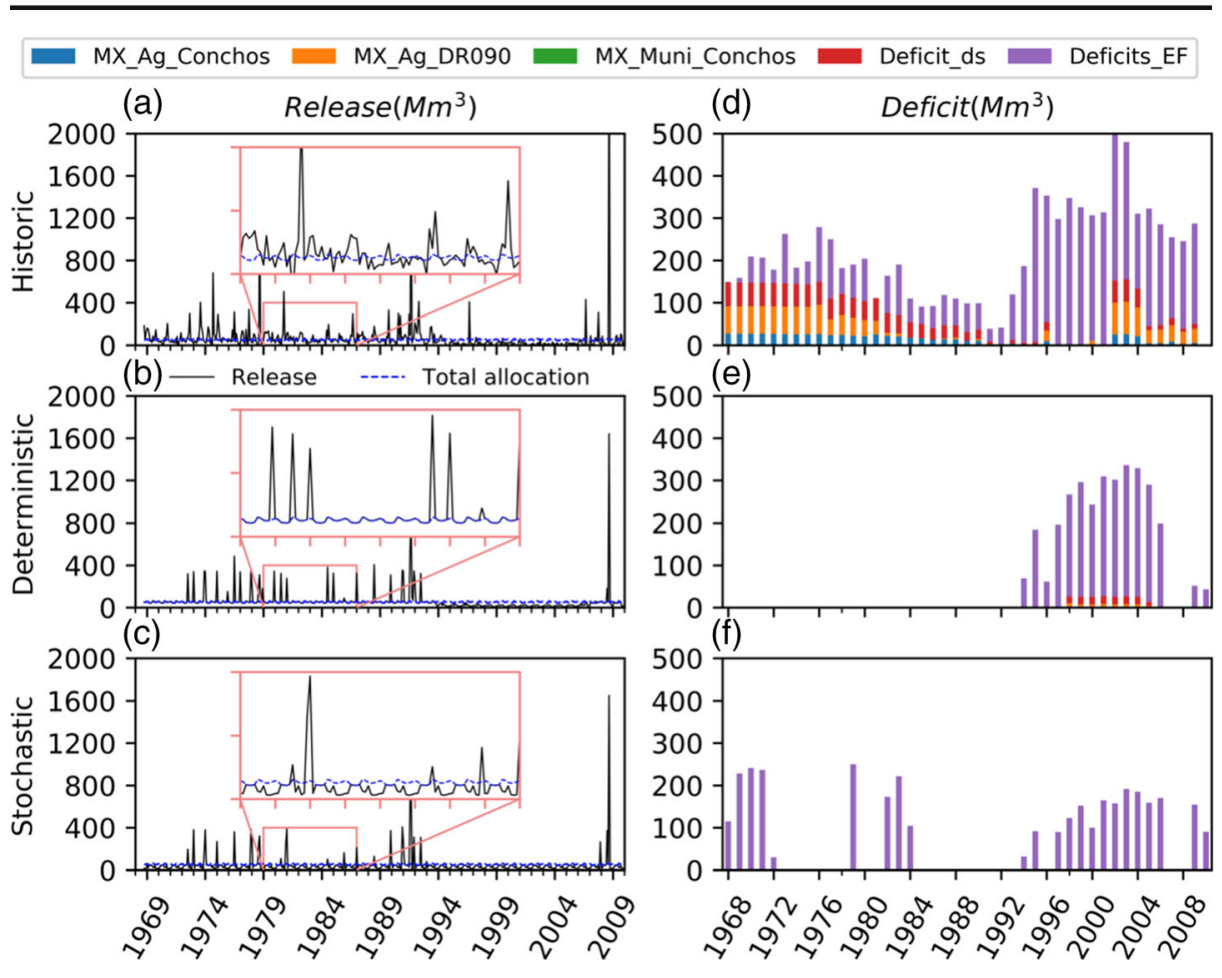

Fig. 3 Historical observation, deterministic, and stochastic reservoir releases and system deficits. Inset is from 1979 to 1987

(18 million USD/year) and stochastic (18.4 million USD/year) models, when compared to historical operations (6.7 million USD/year).

In relation to the environmental demand, the deterministic model, in particular, shows significant improvements in environmental benefits compared to historical observations because, in general, there is sufficient water to sustain human water demands even while increasing environmental water releases. In the stochastic model, environmental benefits also increase compared to historical observations, although less so than in the deterministic model.

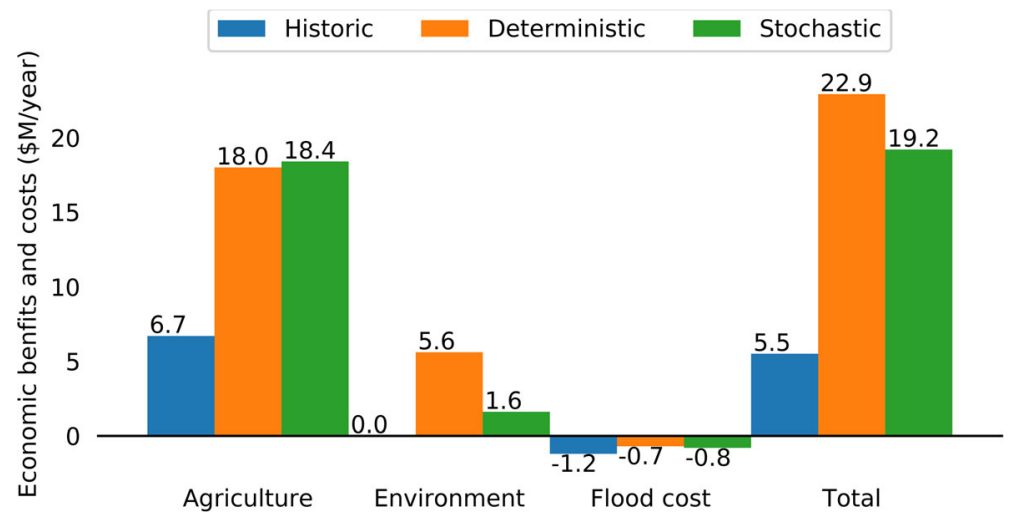

Fig. 4 Comparison between economic benefits and costs under the historical observation, and the deterministic and stochastic models 
It is, however, important to highlight the performance of the stochastic model during prolonged periods of drought (1993 to 2006), when its robust feature reduces the magnitude of deficits even in comparison with the deterministic model. Results from Fig. 4 indicate that the stochastic model could considerably improve the observed economic outcomes and achieve almost the same outcomes simulated by the deterministic model. These results highlight the possibility of enhancing regional economic benefits, even in the absence of reliable climate forecasts through improved reservoir operations.

\subsection{Performance of Reservoir Operations}

Across the calculated performance criteria, the stochastic model improves the system performance considerably with respect to historical operations (Table 1). Such results indicate that it is possible to increase the economic benefits of reservoir management even with uncertain inflows and accounting for environmental water requirements. Historical LLL operations were conservative, making the system unreliable and vulnerable. The deterministic model simulations demonstrate that water availability in the system is enough to meet all demands within the Rio Conchos and improves supply to downstream users and environmental flow allocations.

Environmental water allocation is improved in terms of reliability in timing and volume, particularly under the deterministic model. Given, however, the high vulnerability and low resilience of environmental water allocation, the sustainability index for environmental flows is similar to the historical observation. It is important to note that the geographic location of the environmental flow requirements is far downstream of the reservoir and we did not account for gains and losses of water within the streamflow gauges.

This study highlights the need to consider hydroclimatic variability when designing water management policies. The RGB is an example of a basin with pronounced water resource variability over time. In the Rio Conchos, monthly flow fluctuates from around $2 \mathrm{Mm}^{3}$ to more than $1800 \mathrm{Mm}^{3}$. Many other basins around the world show similar hydroclimatic variability,

Table 1 Comparison of performance of reservoir operation of the historical observation and the deterministic and stochastic models using the different performance criteria

Agricultural area 1 Agricultural area 2 Municipal Downstream demands EF targets

$(\%)$

$(\%)$

$(\%)$

$(\%)$

$(\%)$

\begin{tabular}{lllllll}
\hline Historic & Rel $_{\mathrm{t}}$ & 11.0 & 69.0 & 11.0 & 13.0 & 22.0 \\
& Rel $_{\mathrm{V}}$ & 39.0 & 89.0 & 39.0 & 42.0 & 81.0 \\
& Res & 4.0 & 35.0 & 4.0 & 4.0 & 16.0 \\
& Vul & 68.0 & 36.0 & 68.0 & 67.0 & 24.0 \\
& SI & $\mathbf{2 0 . 0}$ & $\mathbf{6 0 . 0}$ & $\mathbf{2 0 . 0}$ & $\mathbf{2 0 . 0}$ & $\mathbf{4 6 . 0}$ \\
Deterministic & Rel & 99.2 & 97.0 & 100.0 & 92.9 & 72.2 \\
& Rel $_{\mathrm{V}}$ & 99.6 & 98.4 & 100.0 & 94.9 & 100.0 \\
& Res & 100.0 & 100.0 & 100.0 & 22.2 & 15.0 \\
& Vul & 0.0 & 0.1 & 0.0 & 0.4 & 49.5 \\
Stochastic & SI & $\mathbf{9 9 . 7}$ & $\mathbf{9 8 . 8}$ & $\mathbf{1 0 0 . 0}$ & $\mathbf{6 6 . 4}$ & $\mathbf{4 8 . 4}$ \\
& Rel & 100.0 & 100.0 & 100.0 & 100.0 & 49.6 \\
& Rel & 100.0 & 100.0 & 100.0 & 100.0 & 100.0 \\
& Res & 100.0 & 100.0 & 100.0 & 100.0 & 29.1 \\
& Vul & 0.0 & 0.0 & 0.0 & 0.0 & 64.9 \\
& SI & $\mathbf{1 0 0 . 0}$ & $\mathbf{1 0 0 . 0}$ & $\mathbf{1 0 0 . 0}$ & $\mathbf{1 0 0 . 0}$ & $\mathbf{4 7 . 5}$ \\
\hline
\end{tabular}


and this needs to be considered when reservoir operation policies are being designed. Moreover, the results of this study also demonstrate the potential to improve water resource management at a relatively low cost by evaluating and adjusting the current infrastructure operation. Changing system operations does not generally involve costly infrastructure projects and considering the environment has the potential to reduce the cost of restoration activities.

While an increasing number of studies now consider environmental objectives alongside more conventional water demands (Momblanch et al. 2016), challenges remain as to how best to balance these objectives. It has been established that river ecosystems need variability to support different ecosystem functions (Poff et al. 1997). Therefore, in addition to the selected goal of human water supply, this study considered the environment as a demand in the system rather than a minimum flow constraint. This decision acknowledges that the environment requires variable hydrology and also lays the groundwork for achieving greater synergies between environmental and other uses by providing variable flows in the channel when there is sufficient water.

\section{Conclusions}

Unreliable water supply, unmet environmental flow requirements, and flood events are often a consequence of uncertainty and limited knowledge about reservoir inflows. Different approaches have been considered in the literature to identify reservoir releases with respect to time and volume that optimize the objectives of various users, commonly including agriculture, industry, urban water supply, hydropower, flood control, and recreation. The stochastic optimization model proposed in this study presents a risk-informed decision support system for the design of water resource management options to address water scarcity and variability challenges. A novel two-stage stochastic optimization formulation is shown to develop robust operations for a multipurpose reservoir. Results indicate that integrating hydrologic variability into optimization models enables a broader planning spectrum and allows managers to prepare for low probability but costly events. The stochastic model generally outperforms historical reservoir management and performs similarly to the deterministic model with perfect knowledge.

A certain number of simplifying assumptions were used in defining the stochastic optimization model. This model uses a monthly time step that simplifies flood and ecohydrological processes (e.g., inundation plain and flow relationships). Future work should focus on downscaling the model to daily or hourly operations. The model may also benefit from including variability in water demands and using more reliable estimates of economic parameters. Current estimates are considered linear, but costs may be exponential as deficits increase. Lastly, the model does not include water quality parameters, and these should be considered for a complete environmental assessment.

Despite all these limitations, the proposed optimization model can be particularly useful for improving operations under increasing hydroclimatic uncertainty and more intense and frequent droughts and floods with the impending climate change. Thousands of reservoirs worldwide remain sub-optimally managed, and operation policies need to continue to be improved to reduce the often high social and environmental costs of reservoir management and to identify synergies between human and environmental water management objectives. 
Acknowledgments Work by the first author was developed during the Young Scientist Summer Program (YSSP) at the International Institute for Applied Systems Analysis (IIASA). In addition, the work was partially supported by CONACYT and UCMEXUS.

Funding Information Open access funding provided by International Institute for Applied Systems Analysis (IIASA).

\section{Compliance with Ethical Standards}

Conflict of Interest The authors declare that they have no conflict of interest.

Open Access This article is distributed under the terms of the Creative Commons Attribution 4.0 International License (http://creativecommons.org/licenses/by/4.0/), which permits unrestricted use, distribution, and reproduction in any medium, provided you give appropriate credit to the original author(s) and the source, provide a link to the Creative Commons license, and indicate if changes were made.

\section{References}

Berghuijs WR, Aalbers EE, Larsen JR, Trancoso R, Woods RA (2017) Recent changes in extreme floods across multiple continents. Environ Res Lett 12:114035. https://doi.org/10.1088/1748-9326/aa8847

Brooke A, Kendrick DA, Meeraus A, Rosenthal RE (1988) GAMS: a user's guide. Scientific Press

Butcher WS (1971) Stochastic dynamic programming for optimum reservoir operation. J Am Water Resour Assoc 7:115-123. https://doi.org/10.1111/j.1752-1688.1971.tb01683.x

Cañón J, González J, Valdés J (2009) Reservoir operation and water allocation to mitigate drought effects in crops: a multilevel optimization using the drought frequency index. J Water Resour Plan Manag 135:458465. https://doi.org/10.1061/(ASCE)0733-9496(2009)135:6(458)

Celeste AB, Billib M (2009) Evaluation of stochastic reservoir operation optimization models. Adv Water Resour 32:1429-1443. https://doi.org/10.1016/j.advwatres.2009.06.008

Choong S-M, El-Shafie A (2015) State-of-the-art for modelling reservoir inflows and management optimization. Water Resour Manag 29:1267-1282. https://doi.org/10.1007/s11269-014-0872-z

CONAGUA (2011) Memoria descriptiva de la presa Ing. Luis L. Leon (El Granero), ID 0825, Municipio de Aldama, Chihuahua. Comisión Nacional del Agua, Ciudad de México

CONAGUA (1997-2013) Estadísticas Agrícolas de los Distritos de Riego. Comisión Nacional del Agua, Ciudad de México

Ermoliev YM, Wets RJ-B (1988) Numerical techniques for stochastic optimization. Springer-Verlag, Heidelberg

Ermoliev Y, Ermolieva T, Kahil T, Obersteiner M, Gorbachuk V, Knopov P (2019) Stochastic optimization models for risk-based reservoir management. Cybern Syst Anal 55:55-64. https://doi.org/10.1007/s10559019-00112-z

Ermolieva T, Havlík P, Ermoliev Y et al (2016) Integrated management of land use systems under systemic risks and security targets: a stochastic global biosphere management model. J Agric Econ 67:584-601. https:/doi. org/10.1111/1477-9552.12173

Eum H-I, Kim Y-O, Palmer RN (2010) Optimal drought management using sampling stochastic dynamic programming with a hedging rule. J Water Resour Plan Manag 137:113-122

Farmer WH, Vogel RM (2016) On the deterministic and stochastic use of hydrologic models. Water Resour Res 52:5619-5633. https://doi.org/10.1002/2016WR019129

Gaivoronski AA, Sechi GM, Zuddas P (2012) Balancing cost-risk in management optimization of water resource systems under uncertainty. Phys Chem Earth PT 42-44:98-107. https://doi.org/10.1016/j.pce.2011.05.015

Hashimoto T, Stedinger JR, Loucks DP (1982) Reliability, resiliency, and vulnerability criteria for water resource system performance evaluation. Water Resour Res 18:14-20. https://doi.org/10.1029/WR018i001p00014

Huang Y, Chen X, Li Y, Bao A, Ma Y (2012) A simulation-based two-stage interval-stochastic programming model for water resources management in Kaidu-Konqi watershed, China. J Arid Land 4:390-398. https://doi.org/10.3724/SP.J.1227.2012.00390

Husain A (2012) An overview of reservoir systems operation techniques. Int J Eng Res Dev 4:30-37

IBWC (1944) Treaty for the utilization of waters of the Colorado and Tijuana rivers and of the Rio Grande. International Boundary and Water Commission, Washington, D.C. 
IBWC (1971) Proposed flood control project Rio Grande, Presidio Valley, Texas. International Boundary and Water Commission, Washington, D.C.

Kim Y-O, Eum H-I, Eun-Goo E-G, Ko IH (2007) Optimizing operational policies of a Korean multireservoir system using sampling stochastic dynamic programming with ensemble streamflow prediction. J Water Resour Plan Manag 133:4-14. https://doi.org/10.1061/(ASCE)0733-9496(2007)133:1(4)

Labadie JW (2004) Optimal operation of multireservoir systems: state-of-the-art review. J Water Resour Plan Manag 130:93-111. https://doi.org/10.1061/(ASCE)0733-9496(2004)130:2(93)

Lane BA, Sandoval-Solis S, Porse EC (2015) Environmental flows in a human-dominated system: integrated water management strategies for the Rio Grande/bravo basin. River Res Appl 31:1053-1065. https://doi. org/10.1002/rra. 2804

Macian-Sorribes H, Tilmant A, Pulido-Velazquez M (2017) Improving operating policies of large-scale surfacegroundwater systems through stochastic programming. Water Resour Res 53:1407-1423. https://doi. org/10.1002/2016WR019573

Mateus MC, Tullos D (2017) Reliability, sensitivity, and vulnerability of reservoir operations under climate change. J Water Resour Plan Manag 143:04016085. https://doi.org/10.1061/(ASCE)WR.19435452.0000742

Momblanch A, Connor JD, Crossman ND, Paredes-Arquiola J, Andreu J (2016) Using ecosystem services to represent the environment in hydro-economic models. J Hydrol 538:293-303. https://doi.org/10.1016/j. jhydrol.2016.04.019

Motta de Santana Moreira R, Celeste AB (2017) Performance evaluation of implicit stochastic reservoir operation optimization supported by long-term mean inflow forecast. Stoch Env Res Risk 31:2357-2364. https://doi.org/10.1007/s00477-016-1341-4

Obama B, Calderón-Hinojosa F (2010) Joint statement from president Barack Obama and president Felipe Calderón. In: The White House. https://obamawhitehouse.archives.gov/the-press-office/joint-statementpresident-barack-obama-and-president-felipe-calder-n. Accessed Aug 2017

Ortiz-Partida JP, Lane BA, Sandoval-Solis S (2016) Economic effects of a reservoir re-operation policy in the Rio Grande/bravo for integrated human and environmental water management. J Hydrol: Reg. Stud. 8:130-144. https://doi.org/10.1016/j.ejrh.2016.08.004

Pan L, Housh M, Liu P, Cai X, Chen X (2015) Robust stochastic optimization for reservoir operation. Water Resour Res 51:409-429. https://doi.org/10.1002/2014WR015380

Pereira MVF, Pinto LMVG (1991) Multi-stage stochastic optimization applied to energy planning. Math Program 52:359-375. https://doi.org/10.1007/BF01582895

Poff NL, Allan JD, Bain MB et al (1997) The natural flow regime. BioScience 47:769-784. https://doi. org $/ 10.2307 / 1313099$

Porse EC, Sandoval-Solis S, Lane BA (2015) Integrating environmental flows into multi-objective reservoir management for a transboundary, water-scarce river basin: Rio Grande/bravo. Water Resour Manag 29: 2471-2484. https://doi.org/10.1007/s11269-015-0952-8

Revelle C, Joeres E, Kirby W (1969) The linear decision rule in reservoir management and design: 1, development of the stochastic model. Water Resour Res 5:767-777. https://doi.org/10.1029/WR005i004 p00767

Rio Grande, Rio Grande Estuary, and Lower Laguna Madre Basin and Bay Expert Science Team for the Lower Rio Grande Basin (2012) Environmental flows recommendations report. Final submission to the Environmental Flows Advisory Group, Rio Grande Basin and Bay Area Stakeholders Committee and Texas Commission on Environmental Quality https://www.tceq.texas. gov/assets/public/permitting/watersupply/water_rights/eflows/lowerrgbbest_finalreport.pdf

Rockafellar TR, Uryasev S (2000) Optimization of conditional value-at-risk. J Risk 2:21-41. https://doi. org/10.21314/JOR.2000.038

Saadat M, Asghari K (2019) Feasibility improved stochastic dynamic programming for optimization of reservoir operation. Water Resour Manag. https://doi.org/10.1007/s11269-019-02315-7

Sandoval-Solis S, McKinney DC, Loucks DP (2011) Sustainability index for water resources planning and management. J Water Resour Plan Manag 137:381-390. https://doi.org/10.1061/(ASCE)WR.19435452.0000134

Sayto-Corona D, Silva-Hidalgo H, Sandoval-Solis S, Álvarez-Herrera C, Herrera-Peraza E (2017) Aproximación e impacto directo de ciclones tropicales a la cuenca del río Conchos, Chihuahua, México. Invest. Cienc. 25: $53-61$

Seneviratne SI, Nicholls N, Easterling D et al (2012) Changes in climate extremes and their impacts on the natural physical environment. In: Field CB, Dahe Q, Stocker TF, Barros V (eds) Managing the risks of extreme events and disasters to advance climate change adaptation: special report of the intergovernmental panel on climate change. Cambridge University Press, Cambridge, pp 109-230 
Smith AB (2018) 2017 U.S. billion-dollar weather and climate disasters: a historic year in context. In: NOAA Climate.gov. https://www.climate.gov/news-features/blogs/beyond-data/2017-us-billion-dollar-weather-andclimate-disasters-historic-year. Accessed 8 Jul 2019

Stedinger JR, Faber BA, Lamontagne JR (2013) Developments in stochastic dynamic programming for reservoir operation optimization. World Environmental and Water Resources Congress 2013:1266-1278. https://oi. org/10.1061/9780784412947.125

Thompson DA (2008) The future of large dams: dealing with social, environmental, institutional and political costs, edited by T. scudder. Earthscan, London, 2005. ISBN 184407155 3; 184407338 6, xvii + 389 pp. Land Degrad Dev 19:466-467. https://doi.org/10.1002/ldr.828

Tilmant A, Kelman R (2007) A stochastic approach to analyze trade-offs and risks associated with large-scale water resources systems. Water Resour Res 43. https://doi.org/10.1029/2006WR005094

WCD (2000) Dams and development: a new framework for decision-making: the report of the world commission on dams. World Commission on Dams

Yeh WW-G (1985) Reservoir management and operations models: a state-of-the-art review. Water Resour Res 21:1797-1818. https://doi.org/10.1029/WR021i012p01797

Zatarain Salazar J, Reed PM, Quinn JD, Giuliani M, Castelletti A (2017) Balancing exploration, uncertainty and computational demands in many objective reservoir optimization. Adv Water Resour 109:196-210. https://doi.org/10.1016/j.advwatres.2017.09.014

Publisher's Note Springer Nature remains neutral with regard to jurisdictional claims in published maps and institutional affiliations.

\section{Affiliations}

\section{J. Pablo Ortiz-Partida ${ }^{1,2} \cdot$ Taher Kahil $^{1} \cdot$ Tatiana Ermolieva $^{1} \cdot$ Yuri Ermoliev ${ }^{1} \cdot$ Belize $^{-}$ Lane $^{3} \cdot$ Samuel Sandoval-Solis ${ }^{2} \cdot$ Yoshihide Wada $^{1}$}

1 International Institute for Applied Systems Analysis, Schlossplatz 1, A-2361 Laxenburg, Austria

2 Department of Land, Air and Water Resources, Water Management Lab, University of California, Davis, 1 Shields Avenue, Dept. LAWR, PES 1111, Davis, CA 95618, USA

3 Department of Civil and Environmental Engineering, Utah Water Research Laboratory, Utah State University, 1600 Canyon Rd, Logan, UT 84321, USA 